\title{
Transcriptomic Analysis of Human Skin Wound Healing and Rejuvenation Following Ablative Fractional Laser Treatment
}

Joseph D. Sherrill, Deborah Finlay, Robert L. Binder, Michael K. Robinson, Xingtao Wei, Jay P.

Tiesman, Michael J. Flagler*, Jean M. Loftus ${ }^{1}$, Alexa B. Kimball ${ }^{2}$, Charles C. Bascom and Robert J. Isfort

The Procter \& Gamble Company, Cincinnati, OH USA

${ }^{1}$ Loftus Plastic Surgery Center, Fort Wright, KY USA

${ }^{2}$ Beth Israel Deaconess Medical Center and Harvard Medical School

* Corresponding author

Email: flagler.mj@pg.com 


\section{Abstract}

Ablative fractional laser treatment is considered the gold standard for skin rejuvenation. In order to understand how fractional laser works to rejuvenate skin, we performed microarray profiling on skin biopsies to identify temporal and dose-response changes in gene expression following fractional laser treatment. The backs of 14 women were treated with ablative fractional laser (Fraxel®) and $4 \mathrm{~mm}$ punch biopsies were collected from an untreated site and at the treated sites $1,3,7,14,21$ and 28 days after the single treatment. In addition, in order to understand the effect that multiple fractional laser treatments have on skin rejuvenation, several sites were treated sequentially with either $1,2,3$, or 4 treatments (with 28 days between treatments) followed by the collection of $4 \mathrm{~mm}$ punch biopsies. RNA was extracted from the biopsies, analyzed using Affymetrix U219 chips and gene expression was compared between untreated and treated sites. We observed dramatic changes in gene expression as early as 1 day after fractional laser treatment with changes remaining elevated even after 1 month. Analysis of individual genes demonstrated significant and time related changes in inflammatory, epidermal, and dermal genes, with dermal genes linked to extracellular matrix formation changing at later time points following fractional laser treatment. When comparing the age-related changes in skin gene expression to those induced by fractional laser, it was observed that fractional laser treatment reverses many of the changes in the aging gene expression. Finally, multiple fractional laser treatments resulted in continued changes in gene expression, with many genes either differentially regulated or continuously upregulated with increasing number of treatments, indicating that maximal skin rejuvenation requires multiple fractional laser treatments. In conclusion, fractional laser treatment of skin activates several biological processes involved in 
bioRxiv preprint doi: https://doi.org/10.1101/2021.07.26.453869; this version posted July 27, 2021. The copyright holder for this preprint (which was not certified by peer review) is the author/funder. All rights reserved. No reuse allowed without permission.

wound healing and tissue regeneration, all of which significantly contribute to the rejuvenating effect of fractional laser treatment on aged skin. 


\section{Introduction}

Aging of epithelial tissues, such as skin, is a complex biological phenomenon involving the epidermis, dermis and sub-dermis. Analysis of skin aging using systems biology approaches such transcriptomics, RNASeq, proteomics, etc., have demonstrated that skin aging is a dynamic condition with epidermal, dermal and subdermal aging progressing through different processes (Lener et al., 2006; Makrantonaki et al., 2012; Sextius et al., 2015; Holzscheck et al., 2020; Yan et al., 2013; Blumenberg, 2019; Kuehne et al., 2017; Kimball et al., 2017; Xu et al., 2016; SoleBoldo et al., 2020; Cho et al., 2018; Zou et al., 2020; Haustead et al., 2016). Multiple approaches including chemical peels, dermabrasion, laser treatment (e.g. Fraxel®), non-laser light treatments, needling/microneedling, photodynamic therapy, radiofrequency treatment (e.g. Thermage $\left.{ }^{\circledR}\right)$, ultrasound (e.g. Ultherapy®) and combinations of the above have been utilized to rejuvenate aged skin by activating the innate wound repair processes in both the epidermis and dermis (Humphrey et al., 2016; Fathi et al., 2015; Orringer et al., 2008; Fernandes et al., 2008; Fitzpatrick et al., 1996; Helbig et al., 2010; Pryor et al., 2011; Goldman et al., 2010). Of these approaches, the laser-based wound/repair modality appears to have the best efficacy in terms of rejuvenating both the epidermis and dermis, with fractional laser treatment having the least negative patient experience (Brightman et al., 2009; Helbig and Paasch, 2011).

Lasers have been used since the early 1980 s to deliver skin rejuvenation benefits. The first clinically used laser treatment was total ablative laser-based rejuvenation. This treatment results in significant dermal remodeling and epidermal regeneration that improves both skin texture and tone, however as a consequence of removal of most of the epidermis and significant amount of dermis, long healing times and significant side effect profiles are observed. Nonablative laser 
rejuvenation procedures were subsequently developed, and while these approaches reduced the damage to the epidermis, they had limited rejuvenation efficacy. Next, fractional ablative laser rejuvenation procedures were developed, using a grid pattern of separate individual micrometer laser shots to ablate only a fraction of the epidermis and dermis, resulting in dermal remodeling and improved texture and tone with much faster healing times and a significantly improved side effect profile (Brightman et al., 2009; Papadavid et al., 2003; Tierney et al., 2011; Cicchi et al., 2014). Of these three approaches, ablative laser rejuvenation is considered the best treatment in terms of efficacy for the treatment of photoaging, acne scars and rhytides, although it is associated with serious side effects including long healing times, scarring and delayed onset hypopigmentation. In contrast, because the laser does not injure the epidermis and just heats the dermis, non-ablative laser rejuvenation is very safe but not as effective as ablative lasers in skin rejuvenation. Finally, fractional ablative laser rejuvenation combines both the safety of nonablative laser rejuvenation with the efficacy of ablative laser rejuvenation and has become the new gold standard for skin rejuvenation with long lasting rejuvenation effects in multiple ethnicities at multiple body sites (Brightman et al., 2009; Papadavid et al., 2003; Tierney et al., 2011; Helbig and Paasch, 2011; Tan et al., 2014; Ortiz et al., 2010; Sadick et al., 2009; Kohl et al., 2014; Grunewald et al., 2011).

Fractional laser skin rejuvenation works by creating microscopic thermal holes in a grid pattern through the epidermis and deep into the dermis, thus stimulating dermal and epidermal regeneration while leaving most (up to 95\%) of the epidermis and dermis intact. This allows the laser-induced damage to be more quickly repaired (Hantash et al., 2007; Bedi et al., 2007; Rahman et al., 2009; Tierney et al., 2011; Allemann et al., 2010). The depth and width of the 
thermal damage and laser intensity can be altered to achieve maximal dermal rejuvenation, often with efficacy similar to ablative laser treatment, without lengthy re-epithelialization (2 days for fractional laser versus 2-3 weeks for ablative laser), fewer infections, fewer acneiform eruptions and greatly reduced erythema (Tierney et al., 2011; Cohen et al., 2017; Robati et al., 2017). Significant work has been performed to understand how ablative, non-ablative and fractional lasers work to rejuvenate skin. Histopathological studies have demonstrated that fractional laser treatment of skin results in columnar ablative zones surrounded by thermal coagulation zones containing denatured proteins in the epidermis and dermis. Epidermal repair occurs within 1-3 days, the epidermal/dermal junction is repaired by 7 days while dermal repair takes weeks to months (Bedi et al., 2006; Hantash et al., 2007; Laubach et al., 2006; Trelles et al., 2008). Also observed was an increase in epidermal thickness, an increase in dermal collagens and a decrease in dermal elastin (elastosis) (El-Domyati et al., 2013; El-Domyati et al., 2014). These observations have been confirmed using the non-invasive techniques of confocal microscopy and two-photon microscopy (Longo et al., 2013; Cicchi et al., 2014). Histochemical studies looking at specific proteins demonstrate an increase in collagens (COL-1, COL-3), tropoelastin, vimentin, cytokines (EGF, bFGF, PDGF, VEGF, TGF- $\beta$, FGF9), heat shock proteins (HSP70, HSP47, HSP72), apoptosis markers (annexin-VII, Bcl-2, caspase-9), inflammatory cells (CD3+, CD20+, CD68+, CD31+), proteases (MMP1, MMP3, MMP9, neutrophil elastase) and a decrease in p53 (Prignano et al., 2009; Helbig et al., 2011; Xu et al., 2011; Prignano et al., 2012; Helbig et al., 2009; El-Domyati et al., 2007; Zheng et al., 2014). Gene expression studies (typically using qPCR evaluating a limited number of genes) demonstrate an increase in proteases (MMP1, MMP2, MMP3, MMP9, MMP10, MMP11, MMP13), protease inhibitors (TIMP), hyaluronic acid synthesis enzymes (HAS, HYAL), collagens (COL1A1, COL3A1), extracellular matrix 
components (ELN, EMILIN1), cytokines (IL-1 $\beta$, IL-8), and defensins (CAMP, HBD2) (Helbig and Paasch, 2011; Reilly et al., 2010; Orringer et al., 2012; Starnes et al., 2012; Kislevitz et al., 2020). Many of the observations of the effects of fractional laser treatment on human skin have been confirmed using animal and human skin organotypic models with the advantage that more detailed time courses and larger, more numerous sampling can be performed (Bedi et al., 2007; Park et al., 2012; Jiang et al., 2012; Jiang et al., 2014; Natari et al., 2020; Qu et al., 2019; Amann et al., 2016; Schmitt et al., 2018; Huth et al., 2020; Schmitt et al., 2017; Marquardt et al., 2015; Nogita et al., 2017). These analyses have provided a more complete picture of fractional laser treatment; however, the human and/or in vivo relevance of these findings need to be confirmed by actual human studies. More recently, transcriptomic analyses have been performed using microarrays, gene chips and RNAseq approaches, and have identified several gene expression changes occurring following fractional laser treatment on human skin (Kim et al., 2013; Jiang et al., 2012; Kim et al., 2019). Because of the global nature of these approaches, many gene expression changes have been observed following fractional laser treatment, albeit the generation of a holistic understanding of how this treatment results in skin rejuvenation has been hampered by small and limited sampling. Thus, a study evaluating a larger base size of individuals over longer time periods, with frequent sampling using sensitive transcriptomics, is needed to better understand how fractional laser treatment rejuvenates skin. Here,we present our findings from a detailed time course transcriptomic analysis of in vivo fractional laser treated human skin with the goal of providing a holistic understanding of how fractional laser-induced wounding and healing rejuvenates aged human skin. 


\section{Materials and methods}

\section{Study Design}

This study was approved by the Schulman Associates Institutional Review Board. All subjects provided written informed consent prior to undergoing any study procedures. Fourteen women aged 30-55 with Fitzpatrick skin type I-IV were enrolled in this study. Fractional laser treatments were performed using a Fraxel® laser set to $12 \mathrm{mj}$ and $250 \mathrm{mtz}$ with a $1 \mathrm{~cm}^{2}$ treatment area, with all treatments and biopsy sampling performed by licensed medical personnel. For this study, the 14 study participants were treated on the back at 9 different equally spaced sites between the neck, upper buttocks and the left/right edges of the back with a minimum distance of $5 \mathrm{~cm}$ between each treatment site (plus one untreated site), and all sites were tattooed for site recognition. Sixty minutes prior to Fraxel® laser treatment, the treatment site was dosed with a topical anesthetic (BLT Cream: 20\% benzocaine, 6\% lidocaine, $4 \%$ tetracaine) after which the hand-held Fraxel® laser was moved over the treatment site 8 times. The treatment groups were as follows: (1) single laser treatments at 1, 3, 7, 14, 21 and 28 days before biopsy and (2) multiple laser treatments at 28-day intervals with 1,2,3, and 4 treatments. Following the final treatment, a $4 \mathrm{~mm}$ full thickness biopsy was taken at each site (including a non-treated site), the biopsy site was sutured, and the biopsy sample was placed in a cryotube and flash frozen in liquid nitrogen. A total of 140 biopsy samples were generated for analysis. Study design, cohort description, and sample collection for the aged dermis study has been previously described (Kimball et al., 2018).

\section{Microarray profiling}


Microarray profiling was performed on 140 untreated or laser-treated samples using the HGU219 array (Affymetrix) as similarly described for the aged dermis samples (Kimball et al. 2018). Flash-frozen, bisected $4 \mathrm{~mm}$ full-thickness skin punch biopsies were homogenized in TRIzol reagent (ThermoFisher, Waltham, MA) and total RNA was extracted according to the manufacturer's protocol. RNA was further purified using RNEasy spin columns (QIAGEN, Hilden, Germany). Biotinylated cRNA libraries were synthesized from $500 \mathrm{ng}$ of total RNA using the Affymetrix HT 3' IVT Express kit (Affymetrix, Santa Clara, CA) and ta Beckman Biomek FXp Laboratory Automation Workstation (Beckman Coulter, Brea, CA). Biotinylated cRNA was subsequently fragmented by limited alkaline hydrolysis and then hybridized overnight to the Affymetrix Human Genome U219-96 GeneTitan array. Plates were scanned using the Affymetrix GeneTitan Instrument utilizing AGCC GeneTitan Instrument Control software version 4.2.0.1566. Image data was summarized using Affymetrix PLIER algorithm with quantile normalization. Microarray data from this study as well as the aged dermis study have been deposited in the Gene Expression Omnibus (GEO) under GSE168760 and GSE139300, respectively.

\section{Statistical Analyses}

After rigorous quality check using methods and metrics described by Canales, et al, a linear mixed ANOVA model was fitted to the microarray data using SAS software PROC GLIMMIX, version 9.4 of the SAS System for Windows (Canales et al. 2006). Gene expression (in log scale) of each single treatment site was compared to that of the baseline (day 0) untreated site, and each of the multiple treatment sites was compared to the single treatment site at day 28 . Subject, Affymetrix plate (samples from 14 subjects were processed on two plates with seven subjects per 
plate) and Site were class variables. Subject (nested within Plate) was the random effect in the model. No multiple comparison adjustment was used due to the exploratory nature of the study.

\section{Bioinformatic Analyses}

Gene signature analyses were performed using GeneSpring version 14.8 (Agilent Technologies, Santa Clara, CA). In brief, low-expressed probe sets were removed a minimum expression threshold (>20th percentile across all samples within any one treatment group) and condensed to a single Entrez gene ID using the arithmetic mean. $\log _{2}$ fold changes were calculated for the single treatment sites relative to untreated sites (Day 0) or, for the multiple treatment sites, relative to the single treatment site (Day 28). Hierarchical clustering of the $\log _{2}$ fold change values using Euclidean distance was performed to create the single treatment and multiple treatment dendrograms. Biological pathway enrichment was performed on the filtered single treatment signatures $(p<0.01$, absolute fold change $>1.1)$ and multiple treatment signatures $(p<$ 0.05) using Ingenuity Pathway Analysis version $01 \square 07$ (QIAGEN). Fisher's exact $\mathrm{t}$ test was used to assess significantly associated pathways, and $\mathrm{z} \square$ scores were calculated to predict pathway activation states (activated pathways, $\mathrm{z} \square$ score $>0$; inhibited pathways $\mathrm{z} \square$ score $<0$ ). 


\section{Results}

In order to understand how fractional laser treatment works to rejuvenate human skin, an Affymetrix gene chip based transcriptomic analysis was performed on human skin biopsies from fractional laser treated skin at various time points after a single and multiple treatments. The experimental design was two-fold: (1) to understand the biological process that occurs during healing following one fractional laser treatment, 6 different sites on the backs of 14 individuals were treated with a single fractional laser treatment followed by biopsy sampling of those sites at $1,3,7,14,21$ and 28 days after treatment; and (2) in order to understand if multiple treatments result in better skin rejuvenation, 3 different sites on the backs of the same 14 individuals received either 2, 3 or 4 fractional laser treatments at the same site (with the treatments 28 days apart) followed by biopsy sampling. All the single treatments were compared to an untreated biopsy sample, allowing the use of the same individual as their own control (see Materials and Methods for a detailed description). For single treatment sites, the number of differentially expressed probesets was highest 1 day after treatment and continued to drop throughout the 28day treatment period (Table I). Interestingly, multiple treatments of the same site, spaced 28 days apart, showed an increase in differential gene expression when compared to a single treatment after 28 days (Table I). Investigating the nature of the gene expression changes with time after fractional laser treatment demonstrated both increases and decreases in gene expression with a gradual normalization over time (Figure 1A). Clustering analysis showed several interesting patterns including a sharp increase in gene expression at 1 day post treatment followed by a sharp decline between 3- 7 days post treatment - this cluster contains a number of keratin genes, S100 family alarmin genes and metalloproteinase genes - indicative of early epidermal and dermal wound healing responses. Also observed was a sharp decrease in gene 
expression at 1 day post treatment followed by an increase in expression 3 days post treatment and normalization to background levels by 7 days post treatment of a wide variety of genes. Finally, a sharp decrease in gene expression at 1 day post treatment followed by a gradual increase in expression over the 28 day treatment period - this cluster contains a number of dermal extracellular matrix genes (Figure 1B-D).

\section{Skin wound healing involves inflammatory, epidermal and dermal processes.}

A bioinformatic analysis of the top differentially regulated genes demonstrated a collection of activated inflammation related pathways was differentially regulated as early as 1 day after fractional laser treatment with most inflammatory processes normalized by 14 days post treatment (Table II). Epidermal related biological pathways involving proliferation and migration were similarly activated 1 day after treatment with many of the processes normalized by 7 days post treatment (Table III). Interestingly, in addition to proliferation and movement of epidermal cells, an epidermal-mesenchymal transition pathway was activated 3 to 7 days post treatment (Table III), which returned to baseline levels by day 14. This suggests the epidermis as a potential source for the mesenchymal cells participating in tissue repair at this early stage. Evaluation of dermal related biological pathways were complex with some processes initiating 1 day after fractional laser treatment such as proliferation and differentiation of connective tissue cells while other processes beginning much later such as the formation and maturation of collagen fibrils (Table IV). An analysis of the top 20 molecular functions 28 days post treatment supports the observations that cell death and removal, cell proliferation/movement and extracellular matrix maturation are the key processes during the wound healing process (Table 
V). A more granular display of the top 20 molecular functions over time and with multiple treatments is shown in Supplementary Tables 1-9.

An evaluation of the canonical signaling pathways associated with fractional laser treatment demonstrated that apoptosis/proliferation, stress/inflammation and cell adhesion were the key pathway groupings activated (Table VI). In these 3 key pathway groupings, individual pathways demonstrated unique kinetics with peak activation of some pathways such as remodeling of epithelial adherens junctions, ephrin receptor signaling, cell cycle control, and inflammation (IL6 and IL-8 signaling) occurring at early time points (days $1-7$ ). Other pathways including activated interferon signaling and negative inhibition of MMP signaling remained elevated throughout the time points. Finally, the HOTAIR regulatory pathway remained active the entire 28 days of observation (Table VI and Figure 2).

Fractional laser treatment is very effective in reversing skin aging changes. Thus, the transcriptional changes induced by fractional laser resurfacing were compared with the gene expression changes that occur during facial epidermis and dermis aging. The overlap of genes in common between the fractional laser treatment differentially expressed genes at 28 days post treatment and the differentially regulated genes in 50 versus 20 -year-old epidermis (Figure 3A and $3 \mathrm{~B}$ ) and the 50 versus 20-year-old dermis were compared (Figure 3C and 3D). A large number of genes in common was observed withseveral genes being expressed in opposite directions in the fractional laser samples compared to the 50 versus 20 -year-old epidermis and dermis samples(Figure 2B and 2D). A closer analysis revealed several extracellular matrixrelatedgenes, in particular collagen genes, were the most highly upregulated with fractional laser 
treatment at day 28 yet showed the greatest decrease in expression in aged versus young skin (Figure 3B and 3D; Figure 4A-B). Notably, many of the genes shared across multiple pathways displayed an increasing expression pattern over time following fractional laser treatment while their expression was decreased in 50-year-old individuals (Figure 4C). This indicates one of the major effects of fractional laser treatment is the reversal of the loss of extracellular matrix with skin aging.

Finally, based on the clinical observation that multiple fractional laser treatments result in the best skin rejuvenation outcome, the gene expression changes that occur following 2,3 or 4 sequential fractional laser treatments were examined (Figure 5). When compared to a single fractional laser treatment, increased numbers of differential gene expression changes were observed following 2 treatments (Figure 5A), many of which were maintained following 3 and 4 treatments and some which were only observed following 3 treatments (Figure 5B and 5C). An evaluation of two specific genes illustrated that multiple treatments are required for maximal effect for COL1A1 expression (Figure 5D) and NR4A1 (Figure 5E), albeit with different trajectories. 


\section{Discussion}

In this report, temporal transcriptomic analysis has been utilized to better understand how fractional laser treatment functions to rejuvenate aged skin. We demonstrate that fractional laser treatment induces many biological processes related to wound healing and tissue regeneration, in a highly orchestrated manner, resulting in rejuvenation of long-lived skin macromolecules like components of the extracellular matrix. These data greatly expand the previously published temporal analysis of the effects of laser treatment on skin by providing a much more detailed analysis of the changes in gene expression that occur (whole genome) compared to the approximately 20 genes previously analyzed (Helbig and Paasch, 2011; Reilly et al., 2010; Orringer et al, 2012, Starnes et al., 2012; Kislevitz et al., 2020). In addition, this study greatly extends previous transcriptomic analyses by including more sampling times, larger number of study participants and increased number of laser treatments (Kim et al, 2013; Jiang et al., 2012; Kim et al., 2019).

As part of the wound healing process following fractional laser-induced treatment, immediate gene expression changes were observed indicative of epidermal and dermal repair mediated by keratinocytes, fibroblasts and immune cells which were followed by longer term repair of the dermis mediated by fibroblasts and immune cells. Activation of keratinocytes as early as 1 day post fractional laser treatment is exemplified by the large changes in keratin gene expression and the activation of epithelial cell pathways (necrosis of epithelial tissues, proliferation and cell movement of epithelial cells) and is consistent with current knowledge concerning the speed of epidermal repair following fractional laser treatment (Bedi et al., 2006; Hantash et al., 2007; Laubach et al., 2006; Trelles et al., 2008). Two pathways important in the re-epithelization of a 
wound (ephrin receptor signaling pathway and HOTAIR regulatory pathway) were analyzed in more detail. The ephrin receptor signaling pathway, which is important in wound closure and healing (Nunan et al., 2015), is strongly activated as early as 1 day post treatment followed by a gradual decrease over the 28-day treatment period. The long non-coding RNA HOTAIR regulatory pathway was also activated following fractional laser treatment as would be required for proper wound healing (Shi et al., 2020). Additionally, the large changes in S100 gene expression at 1 day post fractional laser treatment, along with the rapid induction of gene expression of several inflammatory pathways, confirms a quick immune response to the damage and greatly expands previous histochemical study findings(Prignano et al., 2009; Helbig et al, 2011; Xu et al, 2011; Prignano et al, 2012; Helbig et al., 2009; El-Domyati et al., 2007; Zheng et al., 2014).

In the dermis, fibroblast mediated gene expression changes occurred immediately after treatment and continued throughout the four-month observation period. An interesting observation was the early (1 day after treatment) coordinated decrease in gene expression of fibroblast cell death and fibrogenesis pathways with an increase in gene expression of connective tissue growth, proliferation of connective tissue and cell movement of connective tissue pathways. These results indicate a complex fibroblast response to damage which appears to be focused on increasing fibroblast numbers and movement to damaged dermal areas. In contrast, later in the dermal wound healing process we observed an increase in the formation of collagen fibrils, tensile strength of skin, and attachment of cells pathways, all of which indicate a maturation of the wound healing response by synthesis and maturation of the extracellular matrix. The observation of these gene expression changes associated with activated tensile strength of skin, 
in particular, supports a direct relationship between the molecular changes induced by fractional laser treatment and the biomechanical properties of the skin. Activation of this pathway 28 days after treatment is consistent with the delayed onset of the skin appearance benefits following fractional laser treatment, and further supports that the late-stage dermal remodeling processes are crucial to the ultimate cosmetic benefits delivered by this gold standard anti-aging procedure. Together, the temporal analysis of gene expression changes following fractional laser wounding demonstrate a complex, yet orderly, repair process and provides significant insight into which biological processes are required for skin repair and rejuvenation.

Evaluation of the effects of multiple fractional laser treatment demonstrated that each treatment increases the skin rejuvenation response, best exemplified by the increase in COL1A1 and other extracellular matrix genes, with at least 2-3 treatments needed for maximal increase in gene expression. An evaluation of NR4A1, a nuclear receptor that functions as a transcriptional repressor of TGF- $\beta$ targeted genes whose expression is decreased during wound healing (Palumbo-Zerr et al., 2015), demonstrated at least 3 fractional laser treatments were required before NR4A1 levels increased to pretreatment levels. These observations fit well with the clinical experience in which maximal skin rejuvenation is observed following multiple fractional laser treatments (Allemann et al., 2010).

Multiple cosmetic procedures work to rejuvenate skin by activating the wound repair process (e.g., Fraxel® Thermage ${ }^{\circledR}$, Ultherapy $\left.{ }^{\circledR}\right)$, which among these approaches fractional laser is considered the gold standard treatment for aging related skin rejuvenation. The analysis of the gene expression changes observed following fractional laser treatment identified many biological 
and molecular pathways that are activated following treatment. These pathways were compared to the biological pathways that are modulated during skin aging using our previously described aging transcriptomics dataset (Kimball et al., 2017), in order to better understand how this treatment works for skin rejuvenation. A large number of genes in common between fractional laser treatment and aging of both the epidermis and dermis of human skin were observed, with treatment leading to reversal of many aging associated gene expression changes. These findings suggest that fractional laser treatment acts holistically across both epidermal and in dermal compartments to restore a more youthful skin structure. Many of the key biological processes affected by fractional laser treatment that are instrumental in skin rejuvenation are the processes involved in the regeneration of the dermal extracellular matrix. Reversal of the age associated loss of extracellular matrix gene expression (most notably collagen genes) was observed along with changes in gene expression indicative of significant remodeling of the extracellular matrix. These observations demonstrate that approaches to rejuvenate aged skin should ideally provide these two functions. Interestingly, several material-based approaches that achieve similar increases in extracellular matrix production to rejuvenate skin include peptides (such as matrikines) and combinations of peptides (Schagen 2017, Katayama 1991, Katayama 1993) and retinoids (Shao et al., 2017; Kong et al., 2016). Together these observations provide evidence that maximal skin rejuvenation requires a multi-faceted approach addressing both epidermal and dermal aging, with a key driver being the modulation of the long-lived dermal extracellular matrix. The transcriptome-wide effects of fractional laser induced skin repair and rejuvenation, analyzed in the present study with both a high degree of temporal precision and across multiple treatments, provides many new potential intervention targets to improve the structure, function and appearance of aging skin. 


\section{References}

Allemann IB, Kaufman J. Fractional photothermolysis - an update. Lasers Med Sci 2010; 25:137-144.

Amann PM, Marquardt Y, Steiner T, Holze F, Skazik-Voogt C, Heise R, Baron JM. Effects of non-ablative fractional erbium glasss laser treatment on gene regulation in human threedimensional skin models. Lasers Med Sci 2016; 31:397-404.

Bedi VP, Chan KF, Sink RK, Hantash BM, Herron GS, Rahman Z, Struck SK, Zachary CB. The effects of pulse energy variations on the dimensions of microscopic thermal treatment zones in nonablative fractional resurfacing. Laser Surgery Med 2007; 39:145-155.

Blumenberg M. Skinomics, transcriptional profiling approaches to molecular and structural biology of epiderms. Semin Cutan Med Surg 2019; 38(1):E12-E18.

Brightman LA, Brauer JA, Anolik R, Weiss E, Karen J, Chapas A, Hale E, Bernstein L, Geronemus RG. Ablative and fractional ablative lasers. Dermatol Clin 2009; 27(4):479-489.

Canales RD, Luo Y, Willey JC, Austermiller B, Barbacioru CC, Boysen C, Hunkapiller K, Jensen RV, Knight CR, Lee KY, Ma Y, Maqsodi B, Papallo A, Peters EH, Poulter K, Ruppel PL, Samaha RR, Shi L, Yang W, Zhang L, Goodsaid FM . Evaluation of DNA microarray results with quantitative gene expression platforms. Nat Biotechnol 2006; 24(9): 1115-1122. 
Cho BA, Yoo S-K, Seo J-S. Signature of photo-aging and intrinsic aging in skin were revealed by transcriptome network analysis. Aging 2018; 10(7):1609-1626.

Cicchi R, Kapsokalyvas D, Troiano M, Campolmi P, Morini C, Massi D, Cannarozzo G, Lotti T, Pavone FS. In vivo non-invasive monitoring of collagen remodeling by two-photon microscopy after micro-ablative fractional laser resurfacing. J Biophotonics 2014; 7(11-12):914-925.

Cohen SR, Goodacre A, Lim S, Johnston J, Henssler C, Jeffers B, Saad A, Leong T. Clinical outcomes and complications associated with fractional lasers: a review of 730 patients. Aesth Plast Surg 2017; 41:171-178.

El-Domyati M, Abd-El-Raheem T, Abdel-Wahab H, Medhat W, Hosam W, El-Fakahany H, Anwer MA. Fractional versus ablative eerbium:yttrium-aluminum-garnet laser resurfacing for facial rejuvenation: an objective evaluation. J Am Acad Dermatol 2013; 68(1):103-112. El-Domyati MM, Attia SK, Esmat AM, Ahmad HM, Abdel Wahap HM, Badr BM. Effect of laser resurfacing on p53 expression in photoaged facial skin. Dermatol Surg 2007; 33:668-675.

El-Domyati M, Abd-El-Raheem T, Medhat W, Abdel-Wahab H, Anwer MA. Multiple fractional erbium:yttrium-aluminum-garnet laser sessions for upper facial rejuvenation: clinical and histological implications and expectations. J Cosmetic Dermatol 2014; 13:30-37. 
Fathi R, Pfeiffer ML, Tsoukas M. Minimally invasive eyelid care in dermatology: medical, laser and cosmetic therapies. Clinics Dermatol 2015; 33:207-216.

Fernandes D, Signorini MD. Combating photoaging with percutaneous collagen induction. Clinics Dermatol 2008; 26:192-199.

Fitzpatrick RE, Tope WD, Goldman MP, Satur NM2. Pulsed carbon dioxide laser, trichloroacetic acid, Baker-Gordon phenol and dermabrasion: a comparative clinical and histological study of cutaneous resurfacing in a procine model. Arch Dermatol 1996; 132(4):469471.

Goldman A, Wollina U. Facial rejuvenation for middle-aged women: a combined approach with minimally invasive procedures. Clin Interventions in Aging 2010; 5:293-299.

Grunewald, S, Bodendorf M, Illes M, Kendler M, Simon JC, Paasch U. In vivo wound healing and dermal matrix remodeling in response to fractional $\mathrm{CO} 2$ laser intervention: clinicopathological correlation in non-facial skin. Int J Hyperthermia 2011; 1-8.

Hantash BM, Bedi VP, Kapadia B, Rahman Z, Jiang K, Tanner H, Chan KF, Zachary CB. In vivo histological evaluation of a novel ablative fractional resurfacing device. Lasers Surg Med 2007; 39:96-107. 
Haustead DJ, Stevenson A, Saxena V, Marriage F, Firth M, Silla R, Martin L et al.

Transcriptome analysis of human ageing in male skin shows mid-life period of variability and central role of NFkB. Sci Rep 2016; 6:26846.

Helbig D, Bodendorf MO, Grunewald S, Kendler M, Simon JC, Paasch U.

Immunohistochemical investigation of wound healing in response to fractional photothermolysis.

J Biomed Opt 2009; 14(6):064044.

Helbig D, Paasch U. Molecular changes during skin aging and wound healing after fractional ablative photothermolysis. Skin Res Technol 2011; 17:119-128.

Helbig D, Simon JC, Paasch U. Epidermal and dermal changes in response to various skin rejuvenation methods. Int J Cosmetic Sci 2010; 32(6):458-469.

Helbig D, Mobius A, Simon JC, Paasch U. Heat shock protein 70 expression patterns in dermal explants in response to ablative fractional photothermolysis, microneedle or scalpel wounding. Wounds 2011; 23(3):59-67.

Holzscheck N, Sohle J, Kristof B, Gronniger E, Gallinat S, Wenck H, Winnefeld M, Falckenhayn C, Kaderali L. Multi-omics network analysis reveals distinct stages in the human aging progression in epidermal tissue. Aging 2020; 12(12):12393-12409. 
Humphrey S, Beleznay K, Fitzgerald R. Combination therapy in midfacial rejuvenation. Dermatol Surg 2016; 42 (Suppl 2):S83-88.

Huth L, Marquardt Y, Heise R, Fietkau K, Baron JM, Huth S. Biological effects of hyaluronic acid-based dermal fillers and laser therapy on human skin models. J Drugs Dermatol 2020; 19(9):897-899.

Jiang X, Ge H, Zhou C, Chai X, Ren QS. The role of vascular endothelial growth factor in fractional laser resurfacing with the carbon dioxide laser. Lasers Med Sci 2012; 27:599-606.

Jiang X, Ge H, Zhou C, Chai Z, Deng H. The role of transforming growth factor B1 in fractional laser resurfacing with a carbon dioxide laser. Lasers Med Sci 2014; 29:681-687.

Katayama K, Seyer JM, Raghow R, Kang AH. Regulation of extracellular matrix production by chemically synthesized subfragments of type I collagen carboxy propeptide. Biochemistry 1991; 30:7097-7104.

Katayama K, Armendariz-Borunda J, Raghow R, Kang AH, Seyer JM. A pentapeptide from type I collagen promotes extracellular matrix production. J Biol Chem 1993; 268(14):9941-9944.

Kim D, Chen R, Sheu M, Kim N, Kim S et al. Noncoding dsRNA induces retinoic acid synthesis to stimulate hair follicle regeneration via TLR3. Nat Commun 2019; 10(1):2811. 
Kim JE, Won CH, Bak H, Kositratna G, Manstein D, Dotto GP, Chang SE. Gene profiling analysis of the early effects of ablative fractional carbon dioxide laser treatment on human skin. Dermatol Surg 2013; 39(7):1033-1043.

Kimball AB, Alora-Palli MB, Tamura M, Mullins LA, Soh C, Binder RL, Houston NA, et al. Age-induced and photoinduced changes in gene expression profiles in facial skin of Caucasian females across 6 decades of age. J Am Acad Dermatol 2017; 78(1):29-39.

Kislevitz M, Lu KB, Wamsley C, Hoopman J, Kenkel J, Akgul Y. Novel use of non-invasive devices and microbiopsies to assess facial skin rejuvenation following laser treatment. Lasers Surg Med 2020; 52:822-830.

Kohl E, Meierhofer J, Koller M, Zeman F, Klein A, Hohenleutner U, Landthaler M and Hohenleutner S. Fractional carbon dioxide laser resurfacing of rhytides and photoageing: a prospective study using profilometric analysis. Br J Dermatol 2014; 170:858-865.

Kong R, Cui Y, Fisher GJ, Wang X, Chen Y, Schneider LM, Majmudar G. A comparative study of the effects of retinol and retinoic acid on histological, molecular and clinical properties of human skin. J Cosmet Dermatol 2016; 15(1):49-57.

Kuehne A, Hildebrand J, Soehle J, Wenck H, Terstgen L, Gallinat S, Knott A, Winnefeld M, Zamboni N. An integrative metabolomics and transcriptomics study to identify metabolic alterations in aged skin of humans in vivo. BMC Genomics 2017; 18:169. 
Laubach H-J, Tannous Z, Anderson RR, Manstein D. Skin responses to fractional photothermolysis. Lasers Surg Med 2006; 38:142-149.

Lener T, Moll PR, Rinnerthaler M, Bauer J, Aberger F, Richter K. Expression profiling of aging in the human skin. Exp Gerontol 2006; 41:387-397.

Longo C, Galimberti M, De Pace B, Pellacani G, Bencini PL. Laser skin rejuvenation: epidermal changes and collagen remodeling by in vivo confocal microscopy. Lasers Med Sci 2013; 28:769776.

Makrantonaki E, Brink TC, Zempeli V, Elewa RM, Mlody B, Hossini AM, Hermes B, Krause U, Knolle J, Abdallah M, Adjaye J, Zouboulis CC. Identification of biomarkers of human skin ageing in both genders. Wnt signaling - a label of skin ageing? PLOS ONE 2012; 7(11):e50393.

Marquardt Y, Amann PM, Heise R, Czaja K, Steiner T, Merk HF, Skazik-Voogt C, Baron JM. Characterization of a novel standardized human three-dimensional skin wound healing model using non-sequential fractional ultrapulsed CO2 laser treatments. Lasers Surg Med 2015; 47:257265.

Natari S, Kim KE, Ryu SI, Park JH, Kim I-H. Device induced neocollagenesis: profibrotic response or true neocollagenesis? Lasers Surg Med 2020; 52:1010-1019. 
Nogita T, Maeda T, Shimokata T, Tsuboi R. Cytokine profiling analysis following a non-ablative fractional laser on rat skin. J Dermatol 2017; 44:207-208.

Nunan R, Campbell J, Mori R, Piteluscu ME, Jiang WG, Harding KG, Adams RH, Nobes CD, Martin P. Ephrin-Bs drive junctional downregulation and actin stress fiber disassembly to enable wound re-epithelization. Cell Rep 2015; 13(7):1380-1395.

Orringer JS, Hammerberg C, Hamilton T, Johnson TM, Kang S, Sachs DL, Fisher G, Voorhees JJ. Molecular effects of photodynamic therapy for photoaging. Arch Dermatol 2008; 144(10):1296-1302.

Orringer JS, Sachs DL, Shao Y, Hammerberg C, Cui Y, Voorhees JJ, Fisher GJ. Direct quantitative comparison of molecular responses in photodamaged human skin to fractionated and fully ablative carbon dioxide laser resurfacing. Dermatol Surg 2012; 38(10):1668-1677.

Ortiz AE, Tremaine AM, Zachary CB. Long-term efficacy of a fractional resurfacing device. Lasers Surg Med 2010; 42(2):168-170.

Palumbo-Zerr K, Zerr P, Distler A, Fliehr J, Mancuso R et al. Orphan nuclear receptor NR4A1 regulates transforming growth factor $-\beta$ signaling and fibrosis. Nat Med 2015; 21(2):150-158.

Papadavid E, Katsambas A. Lasers for facial rejuvenation: a review. Int J Dermatol 2003; 42:480-487. 
Park S-H, Kim D-W, Jeong T. Skin tightening effect of fractional laser: comparison of nonablative and ablative fractional lasers in animal models. J Plast Reconstr Aesthet Surg 2012; 65:1305-1311.

Prignano F, Campolmi P, Bonan P, Ricceri F, Cannarozzo G, Troiano M, Lotti T. Fractional $\mathrm{CO}_{2}$ laser: a novel therapeutic device upon photobiomodulation of tissue remodeling and cytokine pathway of tissue repair. Dermatol Ther 2009; 22:S8-15.

Prignano F, Ricceri F, Bonan P, Cannarozzo G, Campolmi P. Induction of apoptosis by fractional CO2 laser treatment. J Cosmetic Laser Ther 2012; 14:267-271.

Pryor L, Gordon CR, Swanson EW, Reish RG, Horton-Beeman K, Cohen SR. Dermaplaning, topical oxygen and photodynamic therapy: a system review of the literature. Aesth Plast Surg $2011 ; 35(6): 1151-1159$.

Qu Y, Wang Y, Zhang Y, Han C, Gao D, Jin W, Liang J, Xia X. The comparison of skin rejuvenation effects of vitamin A, fractional laser, and their combination on rat. J Cosmet Laser Ther 2019; 21:19-27.

Rahman Z, MacFalls H, Jiang K, Chan KF, Kelly K, Tournas J, Stumpp OF, Bedi V, Zachary C. Fractional deep dermal ablation induces tissue tightening. Lasers Surg Med 2009; 41:78-86. 
Reilly MJ, Cohen M, Hokugo A, Keller GS. Molecular effect of fractional carbon dioxide laser resurfacing on photodamaged human skin. Arch Facial Plast Surg 2010; 12(5):321-325.

Robati RM, Asadi E. Efficacy and safety of fractional CO2 laser versus fractional Er:YAG laser in the treatment of facial skin wrinkles. Lasers Med Sci 2017; 32:283-289.

Sadick NS, Smoller B. A study examining the safety and efficacy of a fractional laser in the treatment of photodamage on the hands. J Cosmet Laser Ther 2009; 11:29-33.

Schagen SK. Topical peptide treatments with effective anti-aging results. Cosmetics 2017: $4(16) 1-14$.

Schmitt L, Amann PM, Marquardt Y, Heise R, Czaja K, Gerber PA, Steiner T, Holze F, Baron JM. Molecular effects of fractional ablative erbium:YAG laser treatment with multiple stacked pulses on standardized human three-dimensional organotypic skin models. Lasers Med Sci 2017; $32: 805-814$

Schmitt L, Huth S, Amann PM, Marquardt Y, Heise R, Fietkau K, Huth L, Steiner T, Holzle F, Baron JM. Direct biological effects of fractional ultrapulsed CO2 laser irradiation on keratinocytes and fibroblasts in human organotypic full-thickness 3D skin models. Lasers Med Sci 2018; 33:765-772. 
Sextius P, Marionnet C, Tacheau C, Bon F-X, Bastien P, Mauviel A, Bernard BA, Bernerd F, Dubertret L. Analysis of gene expression dynamics revealed delayed and abnormal epidermal repair process in aged compared to young skin. Arch Dermatol Res 2015; 307:351-364.

Shi Y, Yang R, Tu L, Liu D. Long non-coding RNA HOTAIR promotes burn wound healing by regulating epidermal stem cells. Mol Med Rep 2020; 22(3):1811-1820.

Shao Y, He T, Fisher GJ, Voorhees JJ, Quan T. Molecular basis of retinol anti-ageing properties in naturally aged human skin in vivo. Int J Cosmet Sci 2017; 39(1):56-65.

Sole-Boldo L, Raddatz G, Schutz S, Mallm J-P, Rippe K, Lonsdorf AS, Rodriguez-Paredes M, Lyko F. Single-cell transcriptomes of the human skin reveal age-related loss of fibroblast priming. Commun Bio 2020; 3:188.

Starnes AM, Jou PC, Molitoris JK, Lam M, Baron ED, Garcia-Zuazaga J. Acute effects of fractional laser on photo-aged skin. Dermatol Surg 2012; 38(1):51-57.

Tan J, Lei Y, Ouyang HW, Gold MH. The use of fractional CO2 laser resurfacing in the treatment of photoaging in Asians: five-year long-term results. Lasers Surg Med 2014; 46(10):750-756.

Tierney EP, Eisen RF, Hanke CW. Fractionated $\mathrm{CO}_{2}$ laser skin rejuvenation. Dermatol Ther $2011 ; 24: 41-53$. 
Trelles MA, Velez M, Mordon S. Correlation of histological findings of single session Er:YAG skin fractional resurfacing with various passes and energies and the possible clinical implications. Laser Surg Med 2008; 40(3):171-177.

Xu J, Spitale RC, Guan L, Flynn RA, Torre EA, Li R, Raber I, Qu K, Kern D, Knaggs HE, Chang HY, Chang ALS. Novel gene expression profile of women with intrinsic skin youthfulness by whole transcriptome sequencing. PLOS ONE 2016; 11(11):e0165913. Xu XG, Luo YJ, Wu Y, Chen JZ, Xu TH, Gao XH, He CD, Geng L, Xiao T, Zhang YQ, Chen HD, Li YH. Immunohistological evaluation of skin responses after treatment using a fractional ultrapulse carbon dioxide laser on back skin. Dermatol Surg 2011; 37(8):1141-1149.

Yan W, Zhang L-L, Yan L, Zhang F, Yin N-B, Lin H-B, Huang C-Y, Wang L, Yu J, Wang DM, Zhao Z-M. Transcriptome analysis of skin photoaging in Chinese females reveals the involvement of skin homeostasis and metabolic changes. PLOS ONE 2013; 8(4):e61946.

Zheng Z, Kang H-Y, Lee S, Kang S-W, Goo B, Cho SB. Up-regulation of fibroblast growth factor (FGF) 9 expression and FGF-WNT/ $\beta$-catenin signaling in laser-induced wound healing. Wound Rep Reg 2014; 22:660-665.

Zou Z, Long X, Zhao Q, Zheng Y, Song M, Ma S et al. A single-cell transcriptomic atlas of human skin aging. Dev Cell 2020; S1534-5807(20):30877-7. 
TABLES 
Table I. Kinetic effects of laser resurfacing treatment(s) on gene expression in human skin

\begin{tabular}{cccc} 
Days post-treatment & Number of treatments & Comparison & $\begin{array}{c}\text { No. differentially regulated } \\
\text { probesets }\end{array}$ \\
\hline 1 & 1 & & 24,358 \\
3 & 1 & & 16,754 \\
7 & 1 & vs Day 0 & 11,473 \\
14 & 1 & (untreated) & 10,693 \\
21 & 1 & & 5,456 \\
28 & 1 & & 6,555 \\
\hline 56 & 2 & vs Day 28 & 4,750 \\
84 & 3 & (1 treatment) & 2,017 \\
112 & 4 & & 4,211 \\
\hline
\end{tabular}

${ }^{1}$ Number of statistically significant probe sets (ANOVA $p$-value $<0.05$ ) expressed above the 30th percentile in $\geq 50 \%$ samples in a treatment group 
Table II. Stress and immune response biological pathways associated with laser resurfacing kinetics

\begin{tabular}{|c|c|c|c|c|c|c|c|c|c|c|c|c|}
\hline \multirow[b]{3}{*}{ Annotation } & \multicolumn{6}{|c|}{ z-score ${ }^{1}$} & \multicolumn{6}{|c|}{$-\log 10 p$-value } \\
\hline & \multicolumn{6}{|c|}{ Days Post-Treatment } & \multicolumn{6}{|c|}{ Days Post-Treatment } \\
\hline & 01 & 03 & 07 & 14 & 21 & 28 & 01 & 03 & 07 & 14 & 21 & 28 \\
\hline Activation of leukocytes & $\mathrm{N} / \mathrm{A}$ & 3.59 & 3.96 & 4.85 & $\mathrm{~N} / \mathrm{A}$ & 2.45 & 0.00 & 8.22 & 8.22 & 23.62 & 0.00 & 3.92 \\
\hline Adhesion of immune cells & $\mathrm{N} / \mathrm{A}$ & 5.04 & 4.27 & 4.81 & $\mathrm{~N} / \mathrm{A}$ & $\mathrm{N} / \mathrm{A}$ & 0.00 & 8.18 & 9.59 & 21.44 & 0.00 & 0.00 \\
\hline Antimicrobial response & $\mathrm{N} / \mathrm{A}$ & $\mathrm{N} / \mathrm{A}$ & 2.21 & 2.71 & 1.55 & 1.73 & 0.00 & 0.00 & 10.48 & 4.79 & 12.35 & 4.22 \\
\hline Cell movement of lymphocytes & $\mathrm{N} / \mathrm{A}$ & $\mathrm{N} / \mathrm{A}$ & 4.46 & 4.34 & N/A & $\mathrm{N} / \mathrm{A}$ & 0.00 & 0.00 & 7.62 & 18.89 & 0.00 & 0.00 \\
\hline Cell movemer & $\mathrm{N} / \mathrm{A}$ & 3.32 & 2.69 & 3.62 & N/A & $N / A$ & 0.00 & 12.13 & 10.66 & 15.95 & 0.00 & 0.00 \\
\hline Degranulation of granulocytes & 2.11 & 3.06 & $\mathrm{~N} / \mathrm{A}$ & 2.54 & $\mathrm{~N} / \mathrm{A}$ & $\mathrm{N} / \mathrm{A}$ & 18.10 & 14.10 & 0.00 & 14.25 & 0.00 & 0.00 \\
\hline DNA damage & -1.72 & $\mathrm{~N} / \mathrm{A}$ & N/A & N/A & N/A & $\mathrm{N} / \mathrm{A}$ & 6.83 & 0.00 & 0.00 & 0.00 & 0.00 & 0.00 \\
\hline Endocytosis & 3.04 & 3.71 & 3.02 & 3.34 & N/A & $\mathrm{N} / \mathrm{A}$ & 10.13 & 9.86 & 10.50 & 11.32 & 0.00 & 0.00 \\
\hline Engulfment of & 2.74 & 3.79 & 3.42 & 3.54 & $\mathrm{~N} / \mathrm{A}$ & $\mathrm{N} / \mathrm{A}$ & 9.71 & 8.41 & 9.84 & 11.34 & 0.00 & 0.00 \\
\hline Immune resp & 1.76 & 3.83 & 3.87 & 4.95 & N/A & $N / A$ & 9.45 & 10.96 & 7.40 & 13.65 & 0.00 & 0.00 \\
\hline Metabolism & 3.71 & 1.84 & N/A & 3.10 & N/A & $\mathrm{N} / \mathrm{A}$ & 7.53 & 9.38 & 0.00 & 8.68 & 0.00 & 0.00 \\
\hline Proliferation of immune cells & 1.62 & 2.06 & 2.96 & 1.74 & 1.86 & 1.37 & 8.57 & 11.22 & 9.27 & 26.51 & 3.57 & 3.49 \\
\hline Recruitment of granulocytes & $\mathrm{N} / \mathrm{A}$ & $\mathrm{N} / \mathrm{A}$ & $\mathrm{N} / \mathrm{A}$ & 3.02 & $N / A$ & $\mathrm{~N} / \mathrm{A}$ & 0.00 & 0.00 & 0.00 & 8.76 & 0.00 & 0.00 \\
\hline Response of phagocytes & $\mathrm{N} / \mathrm{A}$ & 3.17 & 2.88 & 4.30 & N/A & $\mathrm{N} / \mathrm{A}$ & 0.00 & 8.64 & 7.93 & 16.92 & 0.00 & 0.00 \\
\hline & 3.66 & 1.87 & N/A & 3.10 & N/A & $\mathrm{N} / \mathrm{A}$ & 8.18 & 9.23 & 0.00 & 8.35 & 0.00 & 0.00 \\
\hline & $\mathrm{N} / \mathrm{A}$ & $\mathrm{N} / \mathrm{A}$ & N/A & 5.39 & N/A & $\mathrm{N} / \mathrm{A}$ & 0.00 & 0.00 & 0.00 & 13.09 & 0.00 & 0.00 \\
\hline $\mathrm{T}$ cell response & $\mathrm{N} / \mathrm{A}$ & $\mathrm{N} / \mathrm{A}$ & N/A & 3.27 & N/A & N/A & 0.00 & 0.00 & 0.00 & 8.11 & 0.00 & 0.00 \\
\hline
\end{tabular}

1 Activation z-score (see Methods); n/a, activation z-score not calculated

2 Fisher's exact $p$-value 
Table III. Epidermal-related biological pathways associated with laser resurfacing kinetics

\begin{tabular}{|c|c|c|c|c|c|c|c|c|c|c|c|c|c|}
\hline & \multirow[b]{3}{*}{ Annotation } & \multicolumn{6}{|c|}{ z-score ${ }^{1}$} & \multicolumn{6}{|c|}{$-\log 10 p-$ value $^{2}$} \\
\hline & & \multicolumn{6}{|c|}{ Days Post-Treatment } & \multicolumn{6}{|c|}{ Days Post-Treatment } \\
\hline & & 01 & 03 & 07 & 14 & 21 & 28 & 01 & 03 & 07 & 14 & 21 & 28 \\
\hline \multirow{3}{*}{$\begin{array}{c}\text { Growth \& } \\
\text { Differentiation }\end{array}$} & Cell movement of epithelial cells & 1.39 & 0.44 & -0.44 & 0.54 & 1.51 & 0.84 & 7.32 & 7.81 & 8.11 & 7.84 & 3.38 & 3.97 \\
\hline & Proliferation of epithelial cells & 2.18 & -1.28 & 0.56 & N/A & N/A & N/A & 8.26 & 10.88 & 7.54 & 0.00 & 0.00 & 0.00 \\
\hline & Necrosis of epithelial tissue & 0.06 & 0.56 & $N / A$ & $\mathrm{~N} / \mathrm{A}$ & $\mathrm{N} / \mathrm{A}$ & $N / A$ & 13.48 & 14.79 & 0.00 & 0.00 & 0.00 & 0.00 \\
\hline
\end{tabular}

${ }^{1}$ Activation z-score (see Methods); $\mathrm{n} / \mathrm{a}$, activation z-score not calculated

${ }^{2}$ Fisher's exact $p$-value 
Table IV. Dermal-related biological pathways associated with laser resurfacing kinetics

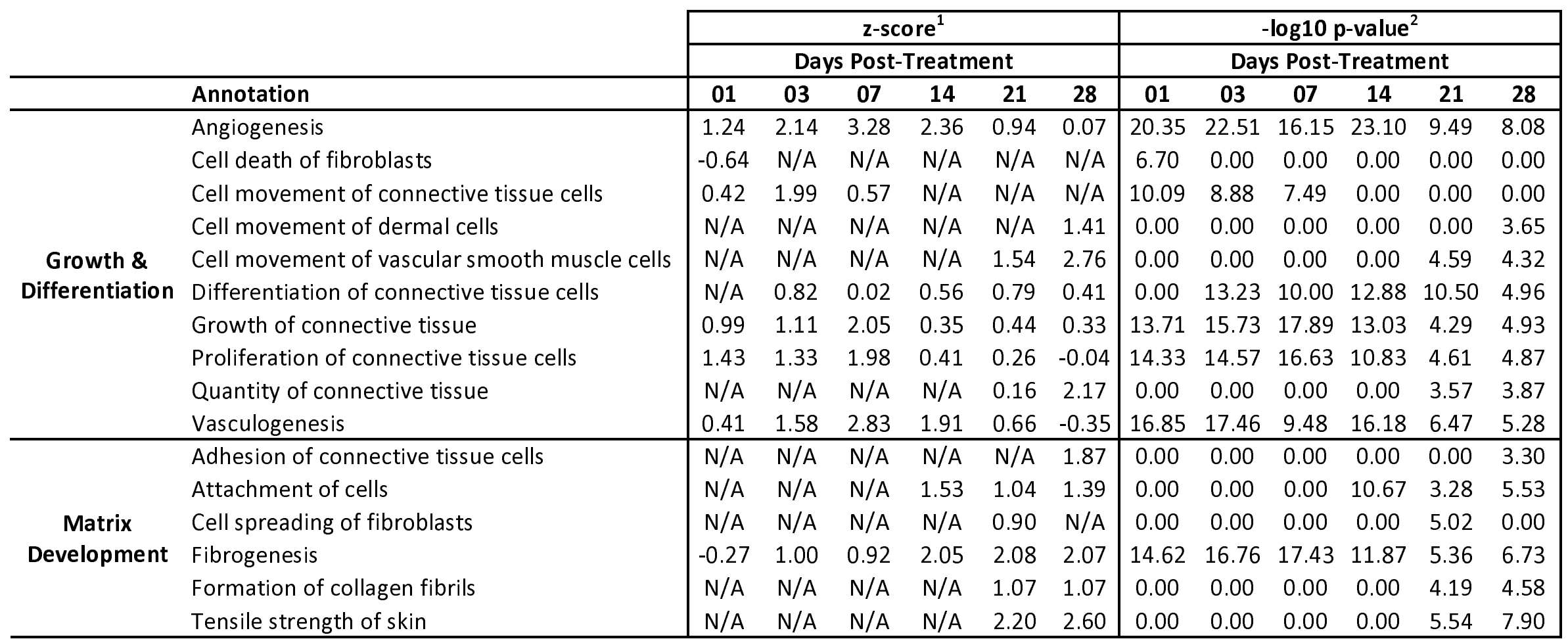

\footnotetext{
${ }^{1}$ Activation z-score (see Methods); n/a, activation z-score not calculated

${ }^{2}$ Fisher's exact $p$-value
} 
Table V. Top 20 molecular functions and system development process annotations associated with day 28 post-laser resurfacing treatment (by Fisher's $p$-value)

\begin{tabular}{|c|c|c|c|}
\hline Annotation & z-score ${ }^{1}$ & p-Value ${ }^{2}$ & \# Molecules $^{3}$ \\
\hline Cell movement & 2.38 & 2.07E-18 & 242 \\
\hline Organization of extracellular matrix & $\mathrm{n} / \mathrm{a}$ & $2.41 \mathrm{E}-17$ & 48 \\
\hline Organization of collagen fibrils & $\mathrm{n} / \mathrm{a}$ & $1.83 \mathrm{E}-14$ & 19 \\
\hline Migration of cells & 2.25 & $7.78 \mathrm{E}-14$ & 208 \\
\hline Necrosis & -0.18 & $9.00 \mathrm{E}-13$ & 250 \\
\hline Apoptosis & -0.04 & $2.60 \mathrm{E}-12$ & 244 \\
\hline Morphology of collagen fibrils & $\mathrm{n} / \mathrm{a}$ & $6.14 \mathrm{E}-12$ & 11 \\
\hline Morphology of fibrils & $\mathrm{n} / \mathrm{a}$ & 8.09E-11 & 12 \\
\hline Metabolism of protein & 1.13 & 4.20E-10 & 125 \\
\hline Abnormal morphology of collagen fibrils & $\mathrm{n} / \mathrm{a}$ & 1.47E-09 & 9 \\
\hline Organization of filaments & 1.90 & $1.79 \mathrm{E}-09$ & 35 \\
\hline Angiogenesis & 0.07 & $8.33 \mathrm{E}-09$ & 106 \\
\hline Tensile strength of skin & 2.60 & $1.27 \mathrm{E}-08$ & 9 \\
\hline Development of vasculature & 0.07 & $2.20 \mathrm{E}-08$ & 113 \\
\hline Initiation of translation of protein & $\mathrm{n} / \mathrm{a}$ & $2.63 \mathrm{E}-08$ & 23 \\
\hline Cell death of tumor cell lines & -0.74 & 2.87E-08 & 152 \\
\hline Quantity of cells & 3.49 & 7.38E-08 & 168 \\
\hline Formation of filaments & 2.19 & $1.61 \mathrm{E}-07$ & 54 \\
\hline Fibrogenesis & 2.07 & $1.87 \mathrm{E}-07$ & 58 \\
\hline Invasion of cells & 0.73 & $4.32 \mathrm{E}-07$ & 101 \\
\hline
\end{tabular}

\footnotetext{
${ }^{1}$ Activation z-score (see Methods); n/a, activation z-score not calculated

2 Fisher's exact $p$-value

${ }^{3}$ Number of genes differentially regulated at day 28 within the annotated pathway
} 
Table VI. Canonical signaling pathways associated with laser resurfacing kinetics

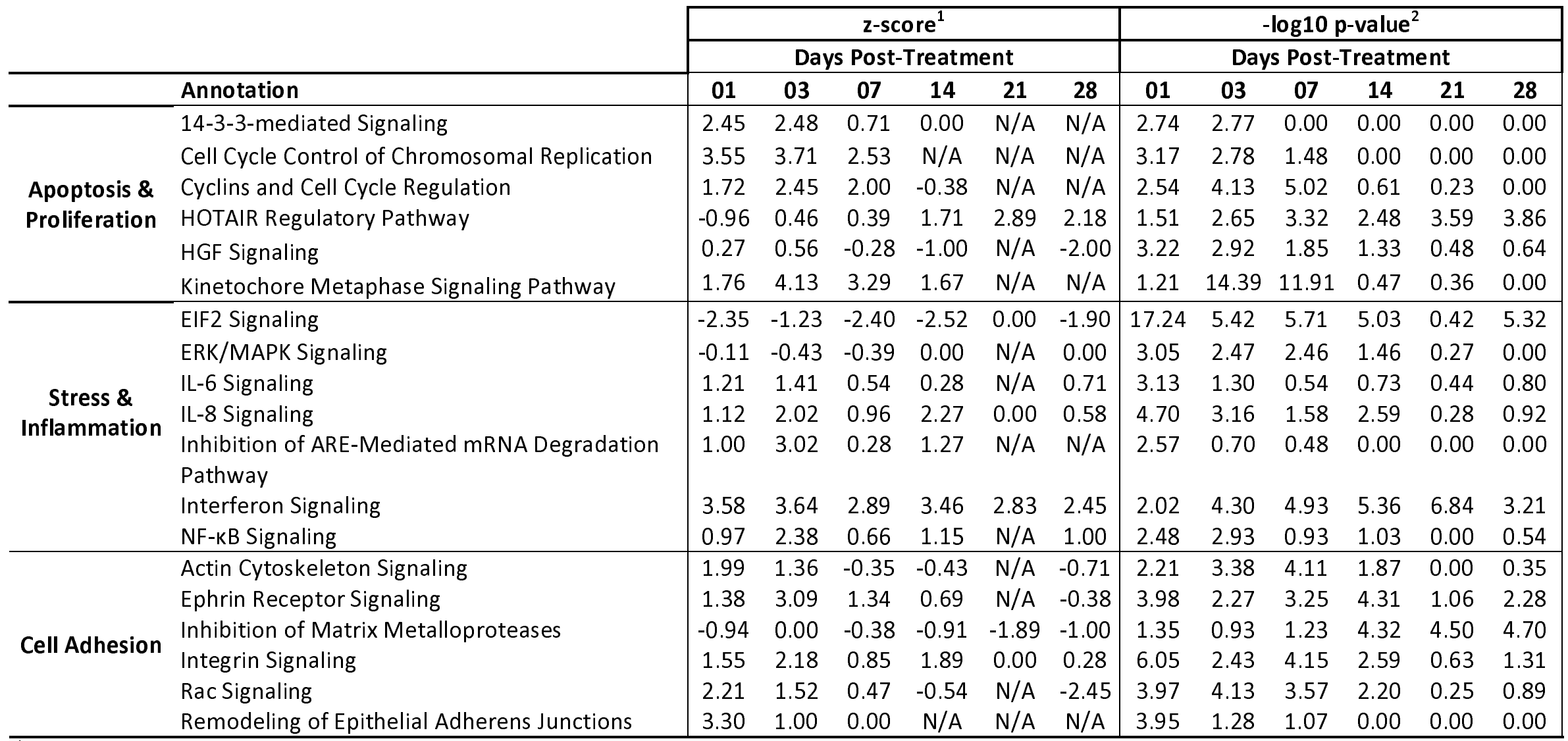

\footnotetext{
Activation z-score (see Methods); n/a, activation z-score not calculated

${ }^{2}$ Fisher's exact $p$-value
} 
FIGURES 
Figure 1. Kinetic effects of single laser resurfacing treatment on gene expression. A) Dendrogram displaying hierarchical clustering of genes by average $\log _{2}$ fold change that were significantly changed at any one time point compared to baseline untreated samples ( $n=15,067$ total). B-D) Dendrograms of select gene clusters from A) showing kinetic dysregulation from early (B, days 1-3), early-tomid (C, days 3-7), and mid-to-late (D, days 14-28) time points following single laser resurfacing treatment. 
A)

Days Post-Treatment:

$\begin{array}{llllll}01 & 03 & 07 & 14 & 21 & 28\end{array}$
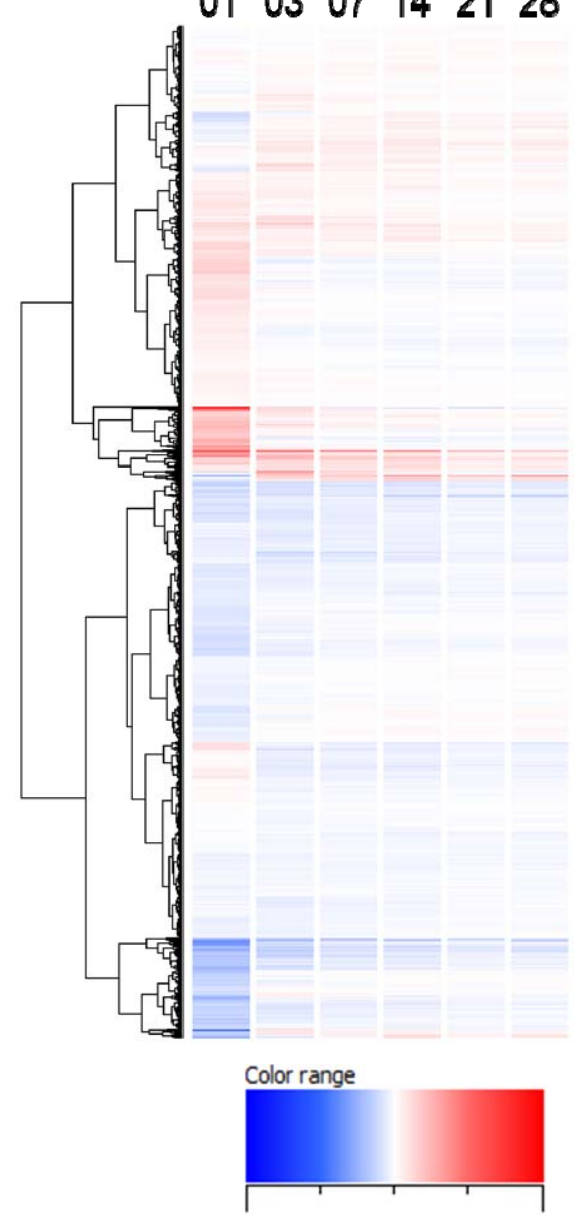

$\begin{array}{llll}-2.3-1.2 & 0 & 1.2 & 2.3\end{array}$
B)

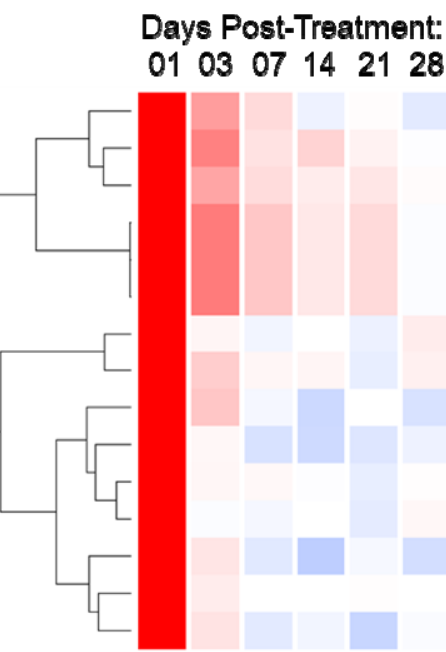

C)
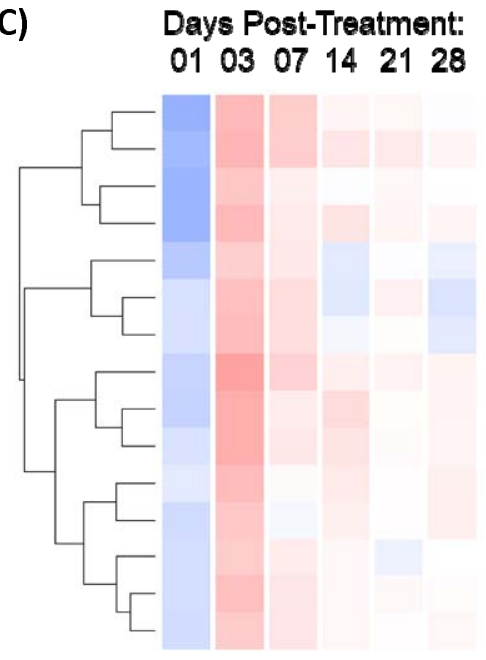

D)

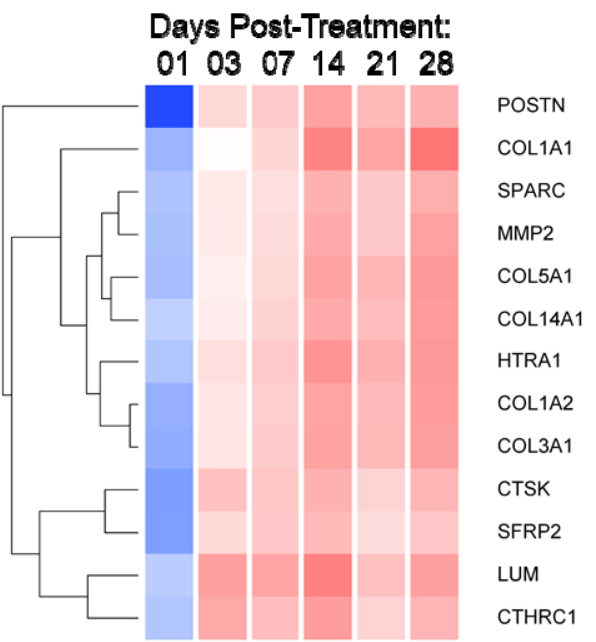

S100A

KRT16///KRT16P1///KRT16P2///KRT16P3 KRT16///KRT16P1///KRT16P2///KRT16P3 KRT16///KRT16P1///KRT16P2///KRT16P3 KRT16///KRT16P1//KRT16P2///KRT16P3 S100A9

KRT6C///KRT6A//IKRT6B

S100A8

S100A7IIIS100A7A

100A7IIIS100A7A

KRT6A///KRT6B///KRT6C

MMP3

SPRR2A

MLANA

SCUBE2

ALDH3A1

FAM83D

KRT15

KRT31

KRTAP26-1

TYR

ANXA9

RNASE7

LIPN

FAM25A

CALML5

SLC24A5

ABCA1 
Figure 2. Single laser resurfacing treatment stimulates signaling pathways associated with wound repair. A) Activation of ephrin receptor signaling at early (days 1-3) time points following single laser resurfacing treatment. Dendrogram shows clustering of genes ( $n=52$ ) involved in the ephrin receptor signaling pathway by average $\log _{2}$ fold change compared to baseline untreated samples. B) Activation of the HOTAIR regulatory pathway at mid-to-late (days 14-28) time points following single laser resurfacing treatment. Dendrogram shows clustering of genes $(n=12)$ involved in the HOTAIR regulatory pathway by average $\log _{2}$ fold change compared to baseline untreated samples. Color scales for z-scores indicate predicted low/inhibition (blue) to high/activation (orange) states for each pathway at a given time point. Color scale for $-\log _{10} p$-value reflect low (white) to high (red) significance for each pathway at a given time point. 
A)

\begin{tabular}{c|cc} 
Days post-treatment & Z-score & -log10 $\boldsymbol{p}$-value \\
\hline $\mathbf{0 1}$ & 1.38 & 3.98 \\
$\mathbf{0 3}$ & 3.09 & 2.27 \\
$\mathbf{0 7}$ & 1.34 & 3.25 \\
$\mathbf{1 4}$ & 0.69 & 4.31 \\
$\mathbf{2 1}$ & $\mathbf{N} / \mathbf{A}$ & 1.06 \\
$\mathbf{2 8}$ & -0.38 & 2.28
\end{tabular}

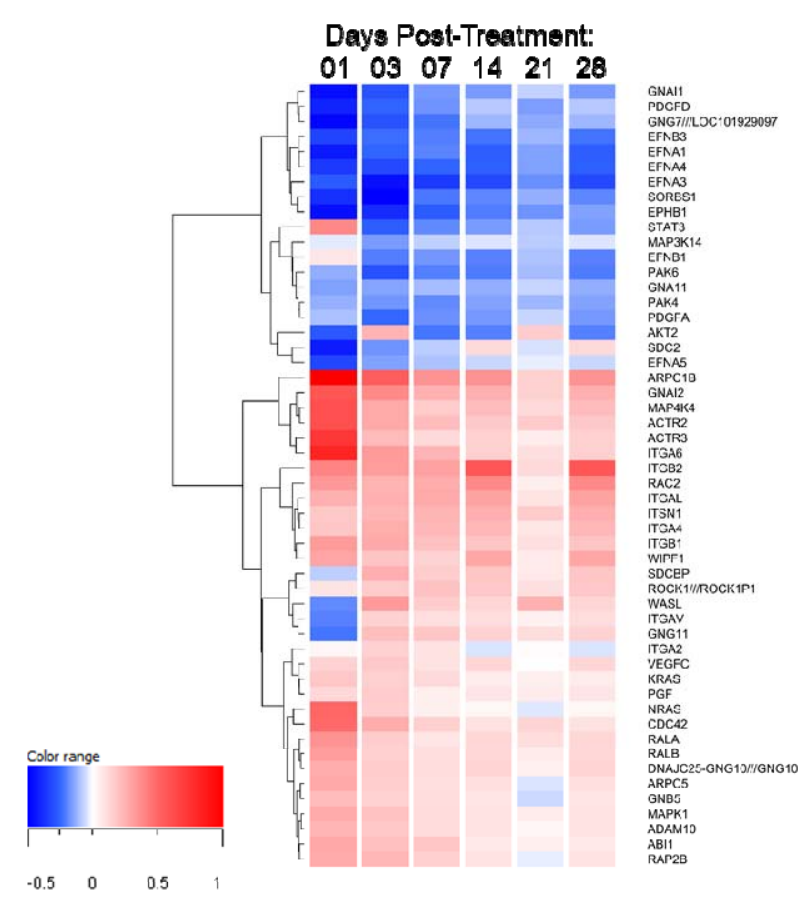

B)

\begin{tabular}{c|c|c} 
Days post-treatment & Z-score & $-\log 10 \boldsymbol{p}$-value \\
\hline $\mathbf{0 1}$ & -0.96 & 1.51 \\
$\mathbf{0 3}$ & 0.46 & 2.65 \\
$\mathbf{0 7}$ & 0.39 & 3.32 \\
$\mathbf{1 4}$ & 1.71 & 2.48 \\
$\mathbf{2 1}$ & 2.89 & 3.59 \\
$\mathbf{2 8}$ & 2.18 & 3.86 \\
\hline
\end{tabular}

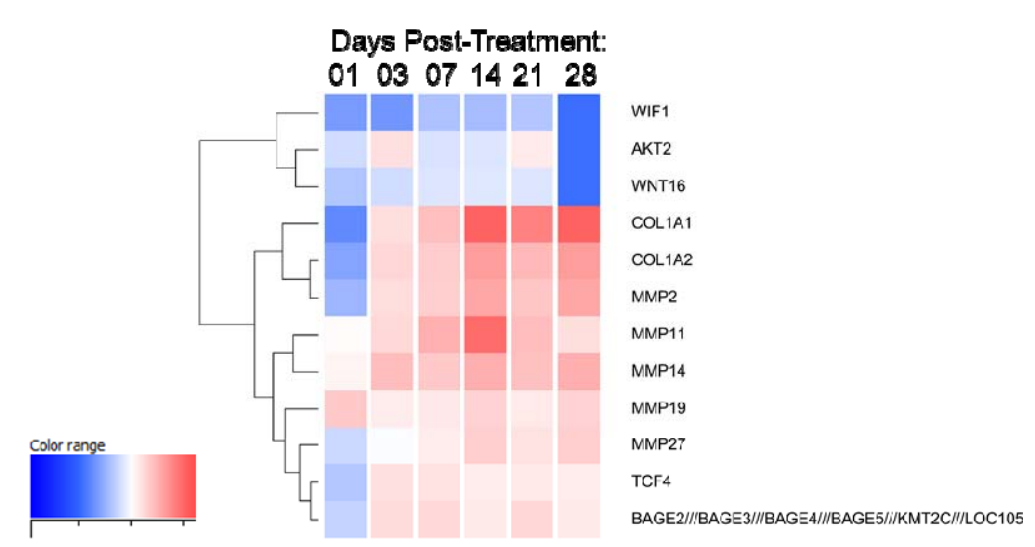


Figure 3. Laser resurfacing treatment reverses age-related gene expression changes. A) Venn diagram depicting the overlap in statistically significant genes altered at 28 days post-laser resurfacing and in facial epidermis between 50-year-olds and 20-year-olds. B) $\log _{2}$ fold change (FC) plot and Pearson correlation for the overlapping genes from A). C) Venn diagram depicting the overlap in statistically significant genes in the laser resurfacing single-treatment kinetic signature and in facial epidermis between 50-year-olds and 20-year-olds. D) $\log _{2}$ fold change (FC) plot and Pearson correlation for the overlapping genes from C).

A)

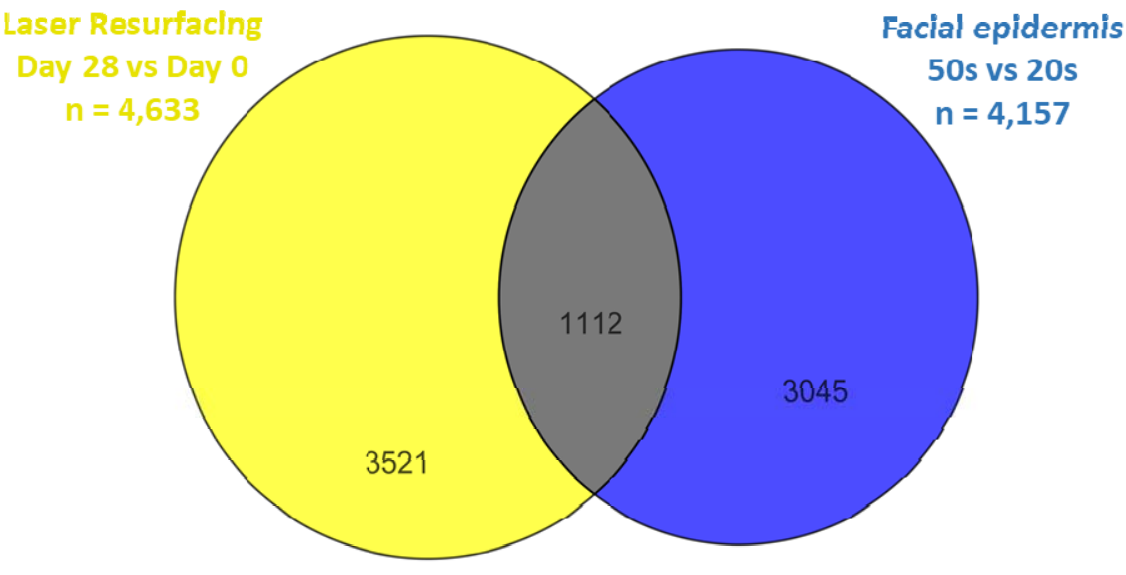

C)

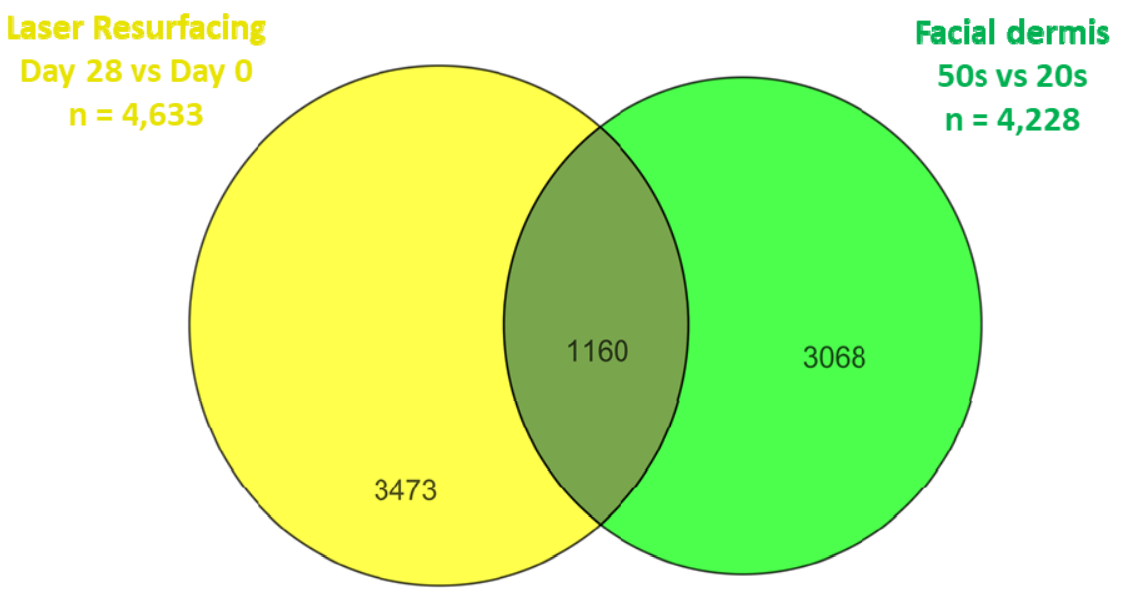

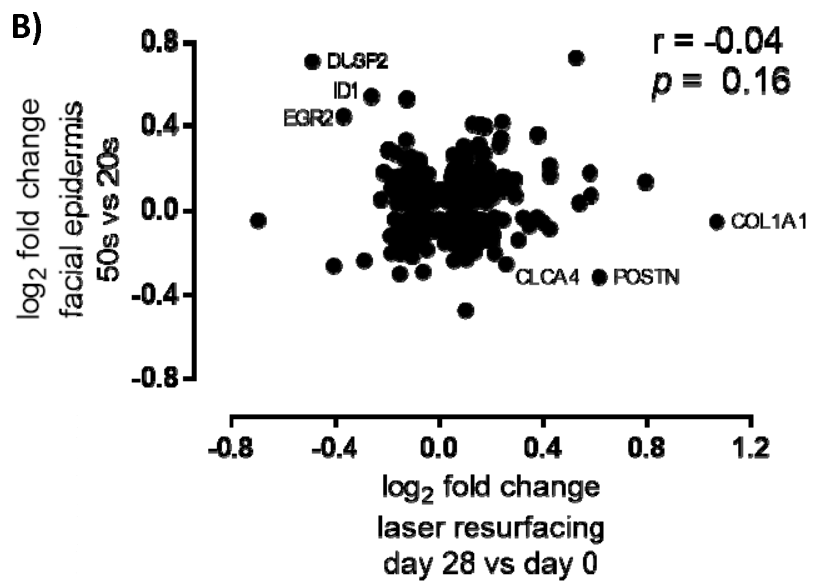

D)

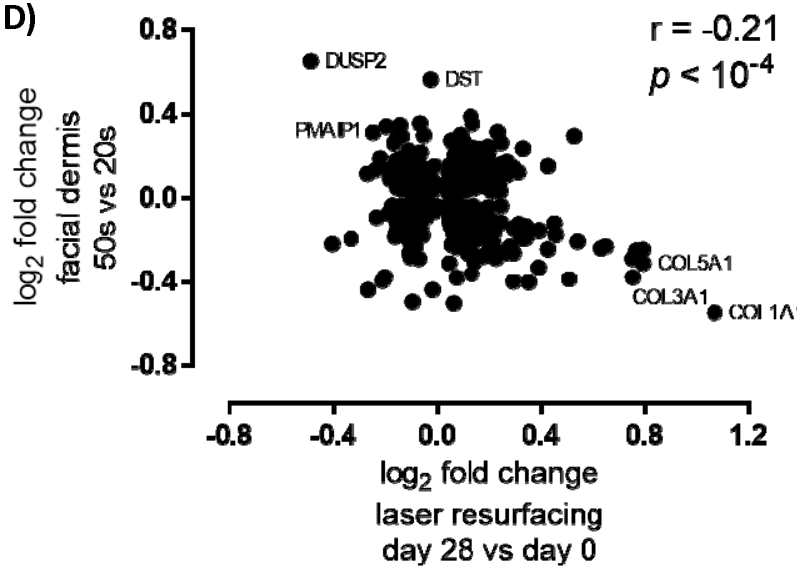


Figure 4. Activation of multiple collagen-related pathways by day 28 post-treatment. A) Bar chart showing top 5 molecular functions and system development processes associated with the day 28 gene signature (by - $\log _{10}$ Fisher's $p$-value). B) Network of shared genes across select collagen-related pathways associated with day 28 gene signature (from Table VI). C) Dendrogram displaying hierarchical clustering of shared collagen across single laser resurfacing treatments (vs. baseline untreated samples) and in facial dermis of 50 -year-olds vs. 20 -year-olds by $\log _{2}$ fold change.

A)

\section{Cellular Movement}

\section{Tissue Development}

Cellular Assembly and Organization

Cellular Function and Maintenance

Cell Death and Survival

B)

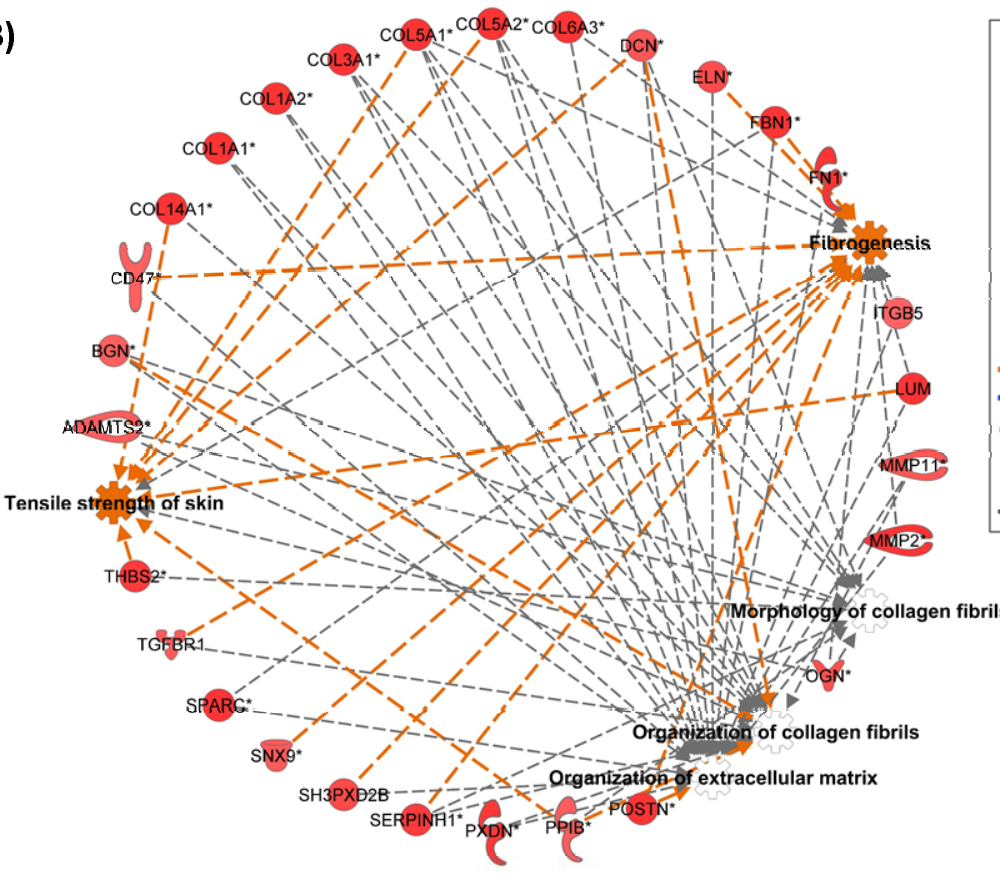

C)

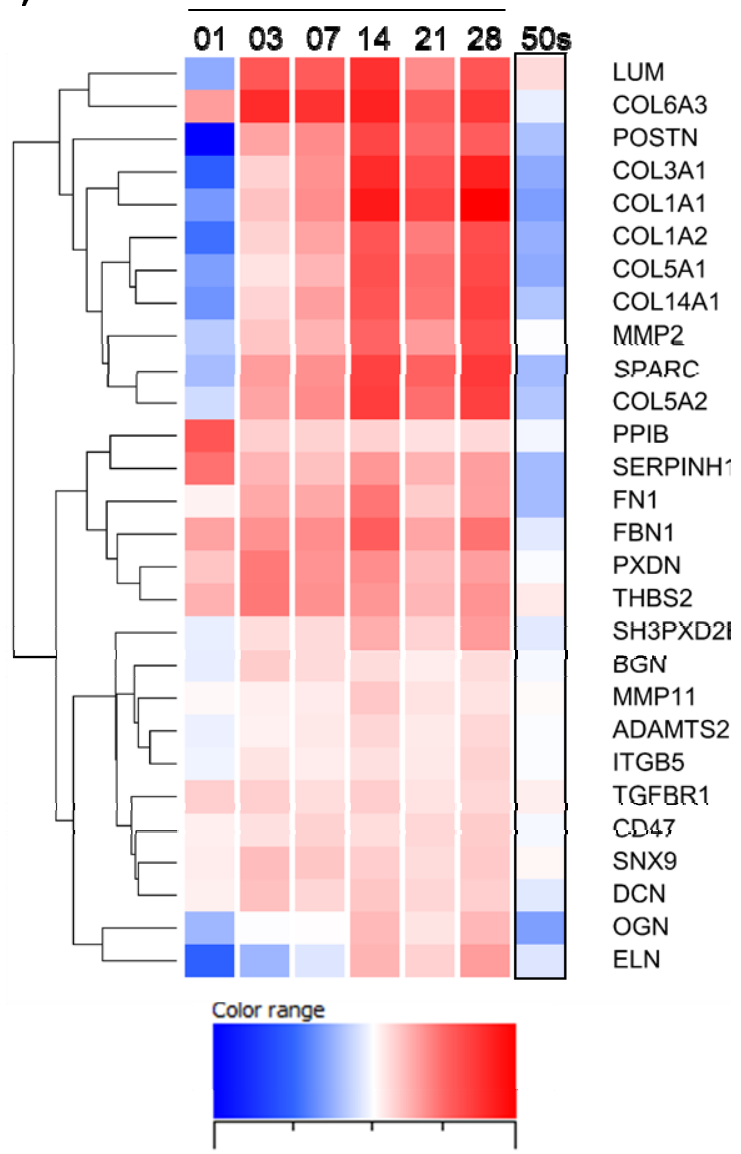

$\begin{array}{lllll}-1.5 & -0.7 & 0 & 0.6 & 1.3\end{array}$ 
Figure 5. Effects of multiple laser resurfacing treatments over time on gene expression. A) Dendrogram displaying hierarchical clustering of genes by average $\log _{2}$ fold change that were significantly changed at any multiple-treatment sites compared to the single-treatment site ( $n=5,795$ total). B-C) Dendrograms of select gene clusters differentially regulated from 2-4 laser resurfacing treatments (B) or continuously upregulated with increasing number of treatments (C). D-E) Profile plots showing normalized expression values ( \pm SEM) of COL1A1 (D) and NR4A1 (E) across the different number of treatments over time. 
A) Number of treatments:

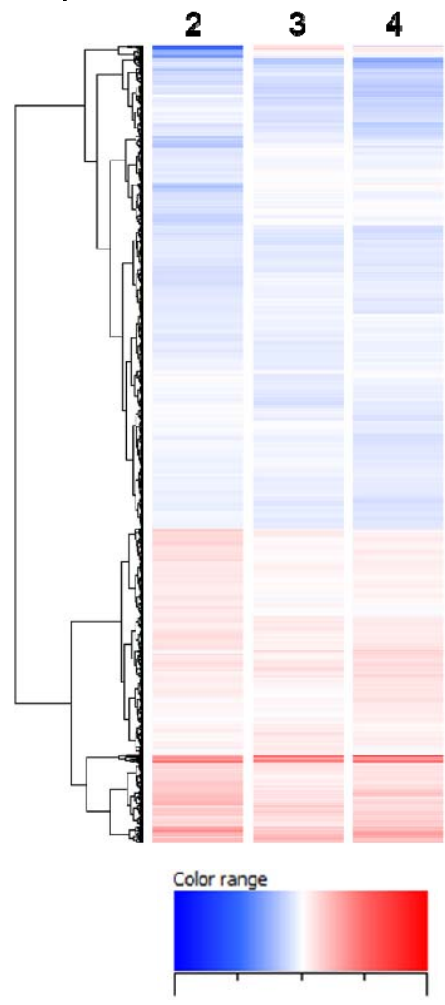

$\begin{array}{ccccc}-0.9 & -0.5 & 0 & 0.5 & 0.9\end{array}$
B) Number of treatments:

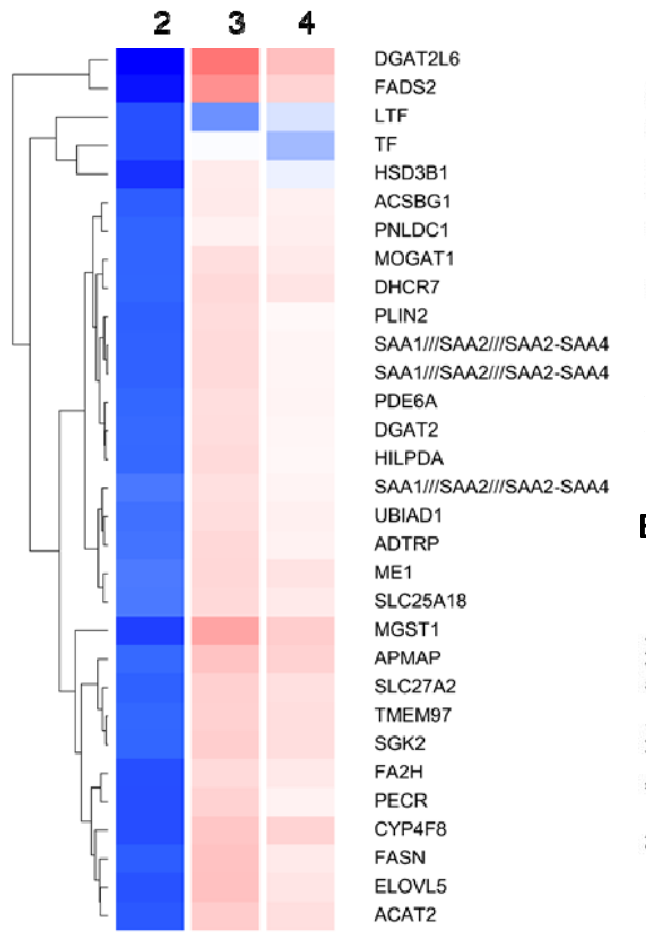

C) Number of treatments

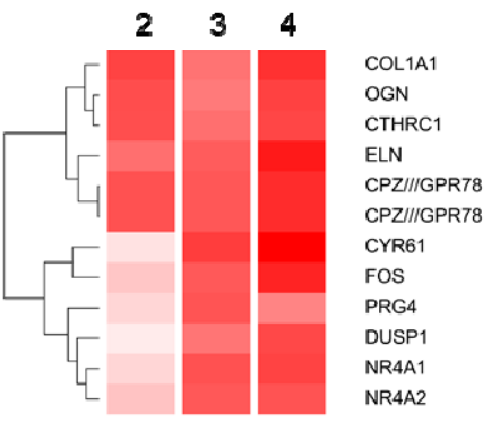

D)

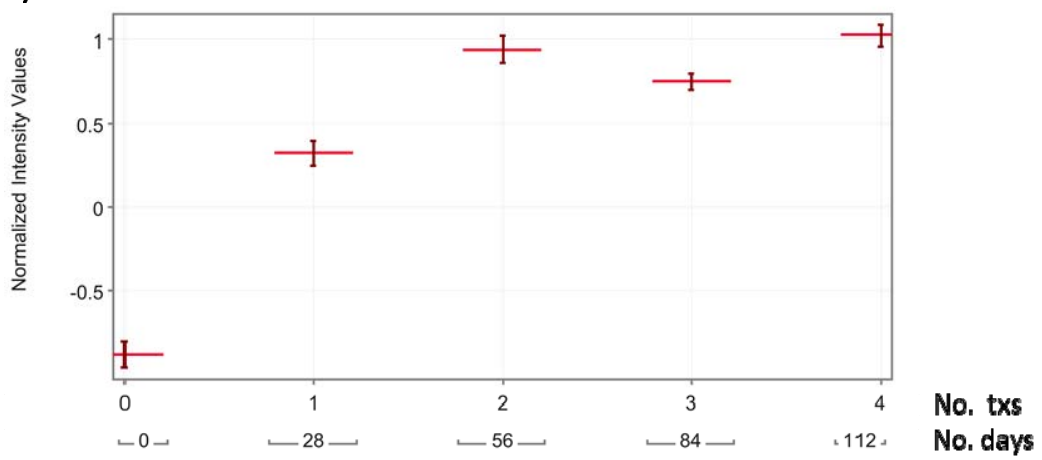

E)

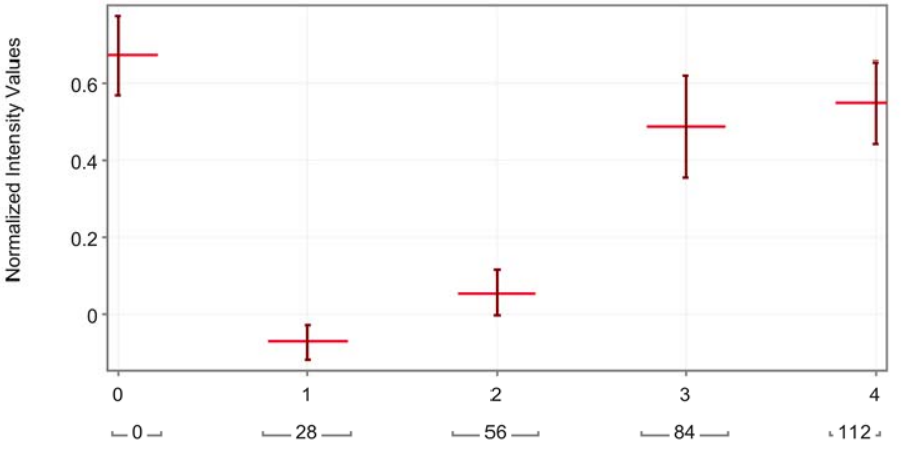

No. txs

No. days 